\title{
Comparing survey and assessment data: Consequences for stock evaluation of Northeast Arctic Greenland halibut*
}

\author{
OLE THOMAS ALBERT ${ }^{1}$ and $\AA$ AE S. HØINES ${ }^{2}$ \\ ${ }^{1}$ Norwegian Institute of Fisheries and Aquaculture, 9291 Troms $\varnothing$, Norway. E-mail: ole.thomas.albert@imr.no \\ ${ }^{2}$ Institute of Marine Research, P.O. box 1870, 5024 Bergen, Norway.
}

\begin{abstract}
SUMMARY: Based on VPA-estimates of abundance, survey data and commercial catch statistics of Northeast Arctic Greenland halibut (Reinhardtius hippoglossoides Walbaum), the paper describes trends by year-class and age in the distribution of Greenland halibut between surveyed and not-surveyed areas. Changes in the distribution of I-group around 1990 to areas beyond the Svalbard surveys has previously been described and related to temperature changes in the Spitsbergen Current. This paper shows that this displaced distribution of the 1989-94 year-classes persisted up to age 7. The results indicate that the displacement was an extraordinary situation and other similar distribution shifts have not occurred during the last 30 years or more. Further, the shift co-occurred with extreme levels of the 137 year long time series of the index of the North-Atlantic Oscillation (NAO). The results are discussed in relation to stock management and climate change.
\end{abstract}

Key words: Greenland halibut, environment, assessment, recruitment, spawning stock, North Atlantic Oscillation, climate change.

\section{INTRODUCTION}

Greenland halibut (Reinhardtius hippoglossoides) is distributed in Arctic and boreal waters on both sides of the North Atlantic (Fedorov, 1971). The Northeast Arctic stock is found along the continental slope outside Norway, including Svalbard, and in the Barents Sea. It spawns along the slope between Norway and Svalbard (Albert et al., 2001b) and Figure 1 shows the main branches of the Atlantic Ocean current system by which eggs and larvae may be transported. Juveniles are found around Svalbard, but may also occur further away from the spawning grounds (Albert et al., 2001a; Bowering and Nedreaas, 2000).

\footnotetext{
*Received December 6, 2000. Accepted March 4, 2002.
}

The fast-growing individuals leave these nursery areas first and may appear in the slope area south of Spitsbergen at age 4-5, while the slow-growing individuals may remain in the nursery areas up to age 10 or more (Albert, in press).

The stock is fished commercially at relatively deep water using gill-nets and longlines at the spawning grounds and by otter trawls in the Barents Sea and along the slope. This is an important fishery that has yielded on average $18000 \mathrm{t}$. annually for the last 20 years (ICES, 2001). Assessment of the stock is carried out annually based on landing statistics and data from research surveys. The main assessment tool is XSA (Shepherd, 1999) tuned with data from Norwegian and Russian surveys in the Barents Sea, along the continental slope of the 


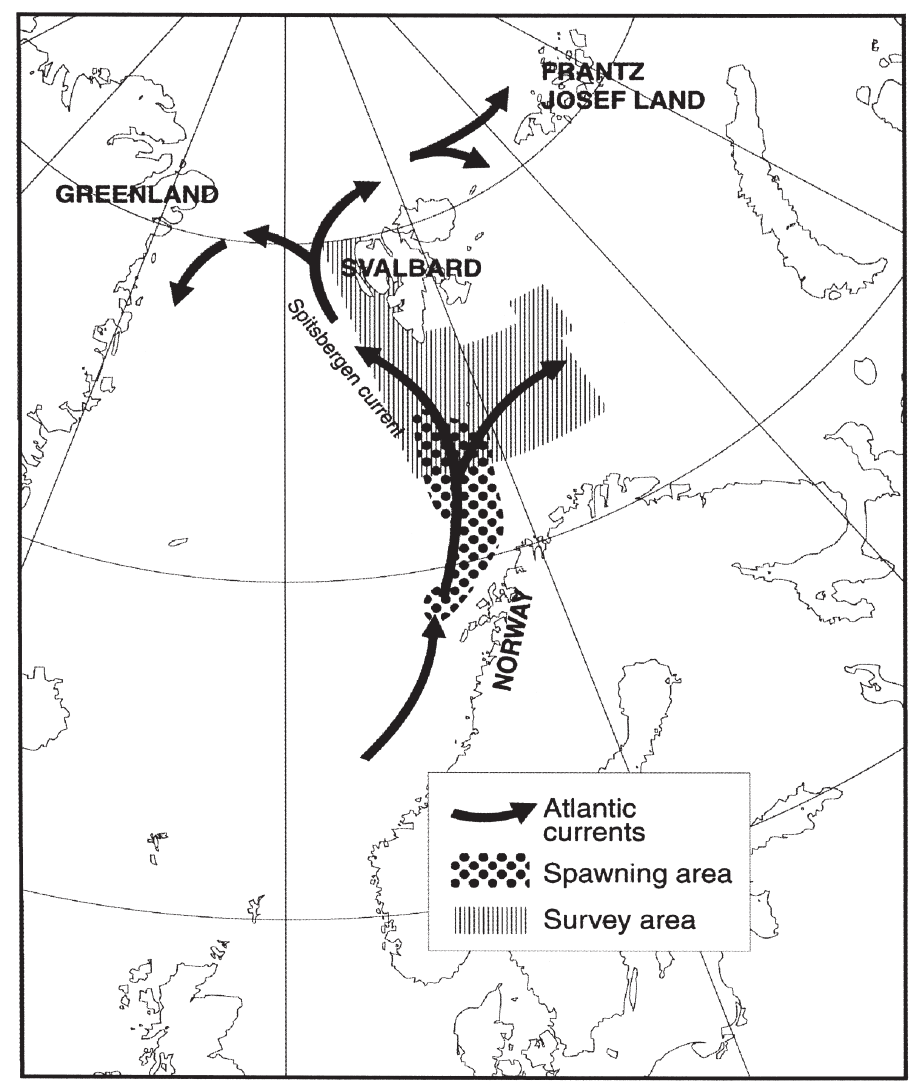

FIG. 1. - Surveyed area and present perception of spawning area of Greenland halibut and transport routes of the spawning products.

Norwegian Sea and in Svalbard waters (ICES, 2001). In the mid 1990s, juveniles had been absent from the surveys for several years and the immediate interpretation was naturally that a recruitment failure had occurred. The proposed causal mechanism was recruitment-overfishing (ICES, 1998), i.e. that the historically low spawning stock was getting below a critical level necessary for maintaining the stock. Subsequent analyses showed that the disappearance of juveniles was associated with a shift in the distribution of juveniles within the survey area in such a way that the reliability of the tuning data was weakened (Albert et al., 1997). Albert et al. (2001a) compared the disappearance of age 1 in the surveys with XSA-results based on catches of the year-classes at older ages and showed that juveniles of the 1989-94 spawning period were distributed outside the survey area to a much higher degree than before. The previously believed weak yearclasses were in fact close to the average and stronger than the preceding ones.

Since the geographical distribution of age 1 Greenland halibut correlated with the sea temperature, it was hypothesised that the causal mechanisms could be related to the latitudinal distribution of spawning activity, the subsequent drift of spawning products, and possibly also to thermotactic migrations of juveniles (Albert et al., 2001b). However, the possibility of interpreting the observed correlation between biological and hydrographical survey data was limited by the short data series having also a high degree of autocorrelation. For evaluating whether the correlation represents a causal relationship long period comparisons are needed.

The purpose of this paper is to establish a longterm history of variation in abundance of juvenile Greenland halibut. The paper evaluates how this history relates to exploitation and the physical environment on a regional scale. Information of juvenile abundance is gathered from the fishery, from older age-groups in the surveys and from expeditions before the start of the standardised survey series. Results are considered in relation to the present perception of the stock status.

\section{METHODS}

Swept area estimates of numbers at age were calculated from a Norwegian stratified bottom 
trawl survey in the Svalbard area (Fig. 1) between 1984 and 1999. A mean of 146 trawls were made in August-September each year at fishing depths of 100-500 m. A Campelen 1800 shrimp trawl with $40 \mathrm{~m}$ sweeps, was used throughout the period. The cod-end was equiped with a $22 \mathrm{~mm}$ mesh sized inner lining. Since 1989 the trawl was equipped with rockhopper ground gear (Engås \& Godø 1989) and strapping was used to stabilize the opening of the trawl. Vaco trawl doors were employed $\left(6 \mathrm{~m}^{2}, 1500 \mathrm{~kg}\right)$ and the standard trawling time was $30 \mathrm{~min}$ at 3 knots. The trawl was equipped with Scanmar sensors that measured the distance between the doors, the trawl's vertical opening and contact with the bottom.

The entire catch or in a few cases a random subsample of Greenland halibut was sorted and measured to the nearest $\mathrm{cm}$ below. From each catch otoliths were taken from five individuals in each 5$\mathrm{cm}$ length-group and read under reflected light. Mean annual number of fish aged was 258 .

Swept area estimates of each age-group were calculated using the method of Jakobsen et al. (1997). The effective swept width was set to $25 \mathrm{~m}$, i.e. between the wing and the door spread. Point observations for fish density at length were summed in $5 \mathrm{~cm}$ length groups and stratified abundance indices for each length group and strata were generated by multiplying with the area $\left(\mathrm{nm}^{2}\right)$ of the stratum. Within each stratum/year number at age was estimated by way of an age/length key. Total number at age within the survey area/year was calculated by summing over all strata.

Survey indices of individual age-groups were very variable (ICES, 2001), since they were based on arithmetic means of highly skewed distributions. Therefore, in order to get a more precise estimate of year-class size, means over three agegroups of each year-class were used to compare with the XSA estimates.

VPA estimates were made with the XSA-software (Shephard, 1999). Tuning series and program settings were similar to the most recent assessment (ICES, 2001), except for the age-span used in the tuning data. While recent assessments used data for ages 5 and older, here we used age 7 as the lowest age in the tuning. The reason for this is the trends in survey-indices at age up to age 7 seen in recent assessments (ICES, 2001). The XSA diagnostics were also similar to the most recent assessment.

Total international catch at age was available for age 3 and older (ICES, 2001). Catch data of juvenile Greenland halibut were also available from controls by Norwegian authorities of the commercial shrimp-trawl fishery during 1980-98. Length samples were available from 1982 and from each of the years 1985-96. No age data were available and approximate compositions of age 0 2 were estimated from the length frequencies. These age-groups constituted well-defined modal groups and according to data from Albert et al. (2001a) may be approximated by the length groups $0-4 \mathrm{~cm}, 5-15 \mathrm{~cm}$ and $16-25 \mathrm{~cm}$ in the first half of the year, and by $0-9 \mathrm{~cm}, 10-19 \mathrm{~cm}$ and $20-$ $28 \mathrm{~cm}$ in the second half.

The distribution of juvenile Greenland halibut was compared with the index of the North-Atlantic Oscillation (NAO). This is a measure of the pressure anomalies in the North Atlantic (Hurrell, 1995) and the winter-index has been shown to correlate with the strength of the Atlantic current outside Norway (Ottersen et al., 2000). This index is available on the Internet at <http://www.cgd.ucar.edu/ jhurrell/ nao.html>.

Albert et al. (2001a) suggested that three mechanisms might be important in linking hydrography to the distribution of juveniles. For an individual year-class each of these mechanisms operates on each of three subsequent years. The latitudinal distribution of spawners is established at age "- 1 " (the year before the 0-group stage) (Albert et al., $2001 \mathrm{~b}$ ); the egg and larval drift operates at age 0 , and active (e.g. thermotactic) migrations may be important at age 1. A three-years-running-mean was therefore used for representing the NAOindex relevant for a year-class. Particular periodicities in this time series were estimated from enhanced peaks in the power spectrum established by Fast Fourier Transform (Stearns, 1975). The significance level (p-value) of these peaks with respect to the null hypothesis of random noise (no periodicity) was estimated by Monte Carlo simulation. Transformation from frequency (f) to length (in years) of the corresponding period $(\mathrm{P})$ is given by:

$$
P=\frac{N}{f}
$$

where $\mathrm{N}$ is 137 , the total number of years in the time series. A rough indication of precision of $\mathrm{P}$ was given as the range:

$$
\frac{N}{f+0.5} \text { to } \frac{N}{f-0.5} .
$$



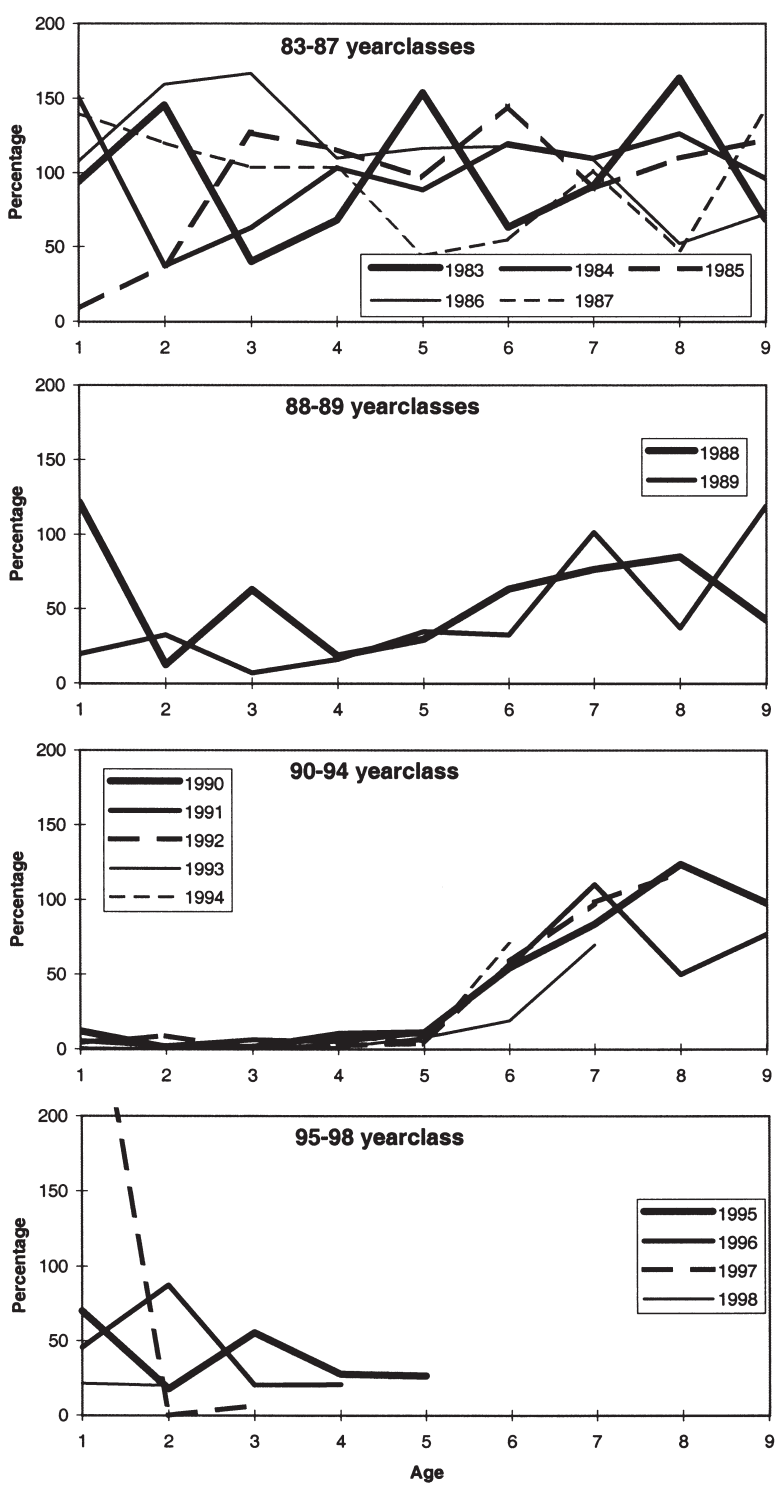

FIG. 2. - Survey abundance by age for individual year-classes. Abundance at age expressed as percentage of the mean abundance of the 1983-87 year-classes at the same age.

\section{RESULTS}

\section{Surveys and assessments}

Figure 2 shows the changes in relative year-class size with age as estimated by the survey indices for each of the year-classes 1983-98. The precision of the estimates at individual age was clearly low. As an example, the 1983 year-class was at age 2, 5 and 8 estimated to be approximately $50 \%$ above the mean of the 1983-87 year-classes at the same ages, while at age 3,6 and 9 it was $50 \%$ below the mean (Fig. 2 top panel). Despite the low precision, there were no apparent trends in relative survey indices by age for any of the year-classes 1983-88. An increas- ing trend with age appeared first for the 1989 yearclass and then much stronger for the 1990-94 yearclasses (Fig. 2 mid panels). Subsequent year-classes were again more abundant at younger age (Fig. 2 lower panel).

Figure 3 shows mean survey indices over three ages together with XSA estimates of abundance of each year-class at different ages. While the survey indices measure abundance within the survey area (Fig. 1), the XSA estimates of numbers at age represent the whole population. There was no close correlation between the two at any age (Fig. 3). The mean survey indices over three ages were much more variable than the XSA estimates. Still the main pattern was that the very low abundance in the surveys of the 1989-94 year-classes at younger ages was not reflected in the XSA (although XSA-estimates are missing for the 1993-94 year-classes). Thus, these year-classes were probably mainly distributed outside the survey area at younger ages and appeared in Svalbard waters when they became older.

The age at which the displaced year-classes returned to the survey area varied. At age 4 the survey indices for the 1989-92 year-classes were 16, 10,5 and $3 \%$ respectively of the mean of the 198387 year-classes at the same age. At age 5 the figures were $35,11,11$ and $4 \%$. At age 6 and 7 the figures were respectively around 50 and $100 \%$ for all of these year-classes. Thus, at age 7 and older, catches of the displaced year-classes were not different from previous year-classes (Fig. 3 lower). However, the earlier of these year-classes seemed to return to the surveyed area at a younger age than the later ones.

\section{Extending the time series of abundance}

In contrast to the 1989-94 year-classes, all yearclasses prior to 1988 were also abundant in the surveys at younger ages. In Figure 3 (middle), survey indices are extended back to the 1980-year-class, before which we have no observations that are directly comparable with the low abundance of the 1989-94 year-classes.

Estimated total international landings of age 3 and 4 (ICES, 2001) were considered in order to further evaluate the occurrence of juvenile Greenland halibut in Svalbard waters prior to the survey time series (Fig. 4). The landings of age 3 and 4 were almost exclusively taken within the survey area of Figure 1 (Norwegian official catch statistics, unpublished data). This is natural, since juveniles are 

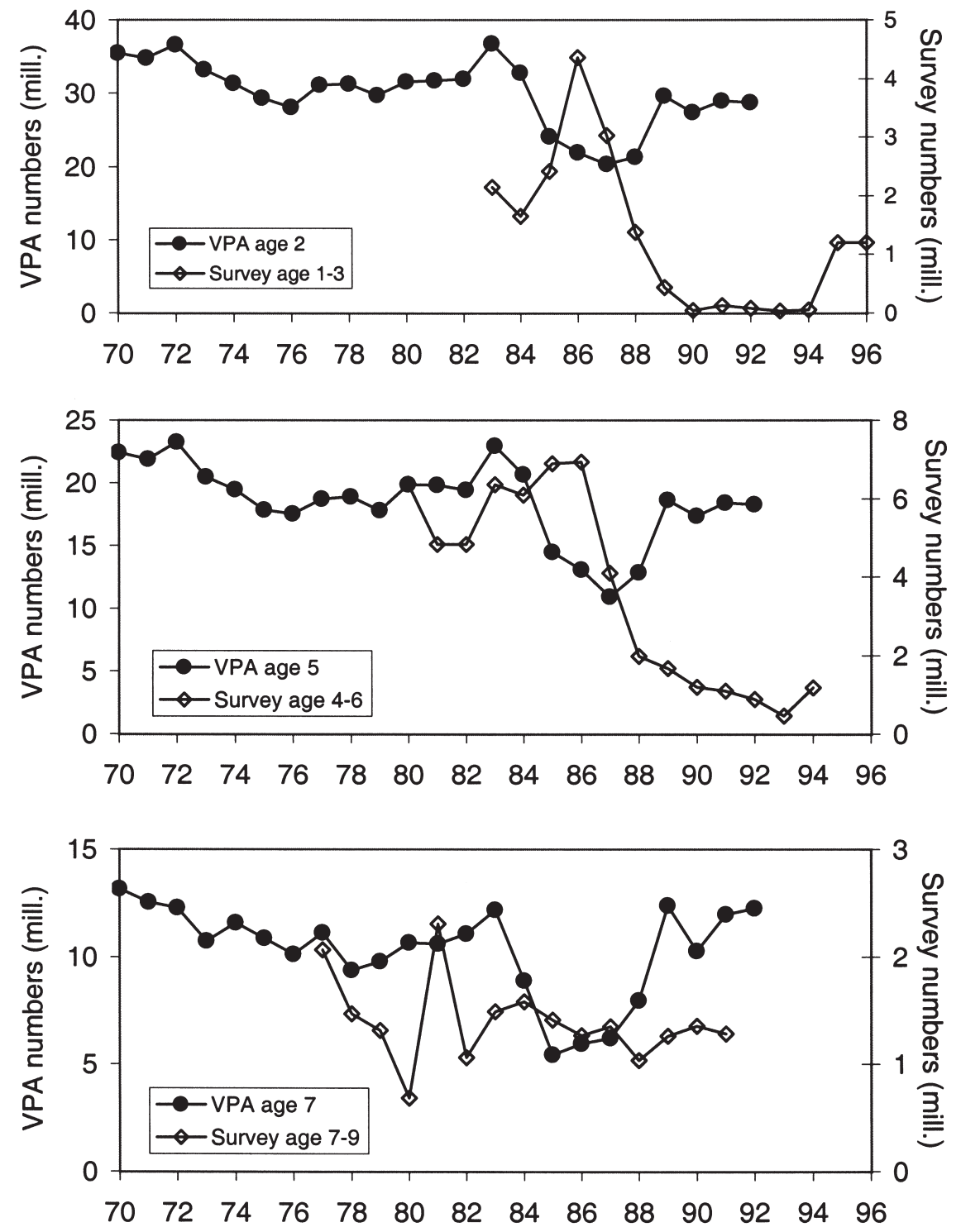

Yearclass

FIG. 3. - Numbers at age within the survey area (swept area estimates) and in the total stock (VPA estimates) for each year-class at selected ages.

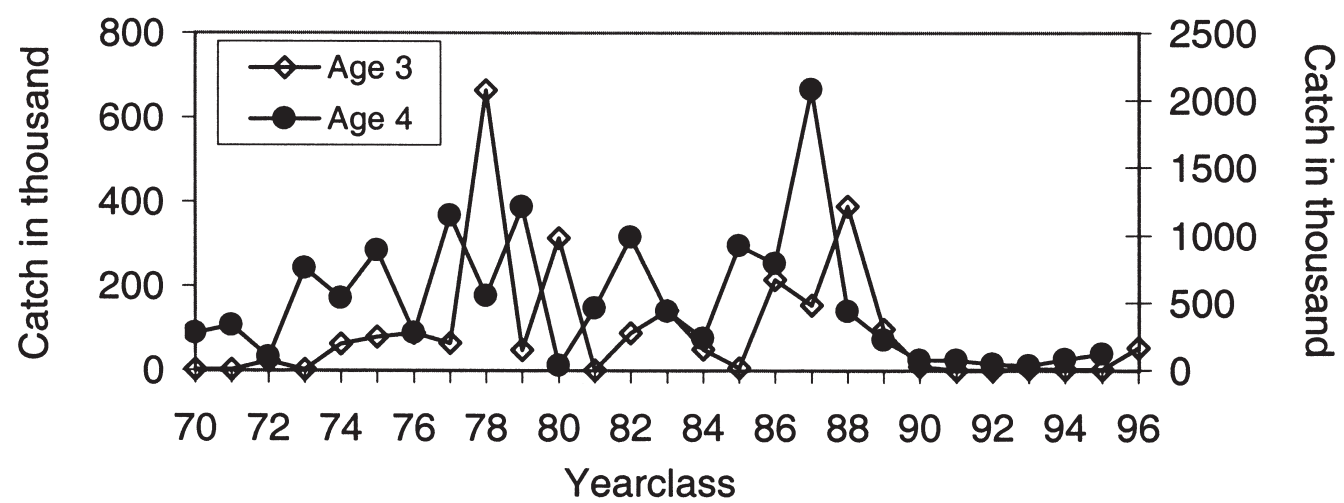

FIG. 4. - Total international landings of Greenland halibut at age 3 and 4 (data from ICES (2001) and unpublished data from Institute of Marine Research, Bergen). 


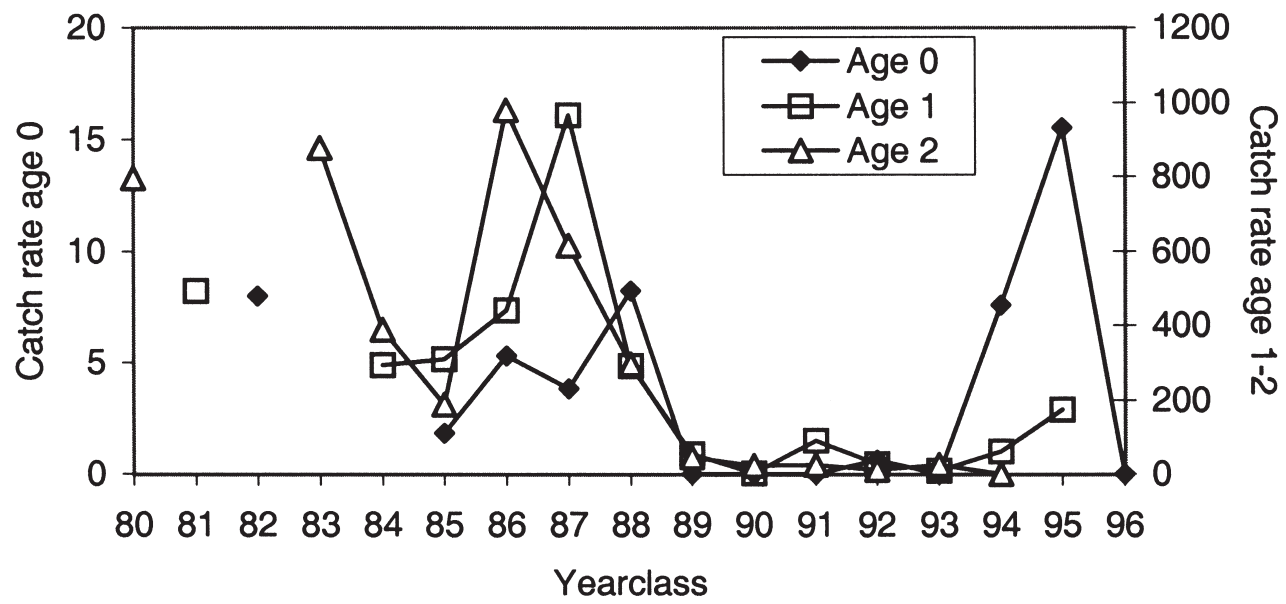

FIG. 5. - Catch rates of Greenland halibut of age 0-2 in the Norwegian commercial shrimp-trawl fishery in the Svalbard Area (data from controls by Norwegian authorities).

scarce south of this area (Albert et al., 2001a) and commercial fishery seldom operate north of this area. Figure 4 shows a series of very low catches of these age-groups from the 1990 year-class onwards. For previous year-classes, at least back to the 1976 year-class, variation in catch was clearly related to a year-effect, i.e. peaks at age 4 due to a particular year-class corresponded to peaks at age 3 of the succeeding year-class. In contrast to this, the 1990 yearclass was first absent from the landings at age 3 (i.e. in 1993) and then at age 4 (i.e. in 1994), thus indicating an effect possibly related to year-class more than to year. Figure 4 also shows that no other similar periods were observed since 1970. In the most recent years catches increased somewhat, as they did in the surveys.

Figure 5 shows by-catch rates of 0,1 and 2 yearold Greenland halibut in the Norwegian commercial shrimp trawl fishery at Svalbard. These catches show the same pattern as above, with near zero catches of the 1989-93/94 year-classes. The disappearance was clearly related to the 1989 year-class and not to year of catch. This year-class effect is in contrast to the peak catch in 1988 of both age 0,1 and 2, i.e. a year effect on each of the 1986-88 yearclasses simultaneously.

\section{Four weak year-classes}

Comparing XSA with survey and commercial catches (Figs. 2-5) also shows another pattern consistent over several ages and years. The relatively low abundance of the 1985-88 year-classes in the XSA, shown in Figure 3 for ages 2, 5 and 7, was not seen in the surveys or in the commercial landings. The low abundance of these year-classes was con-

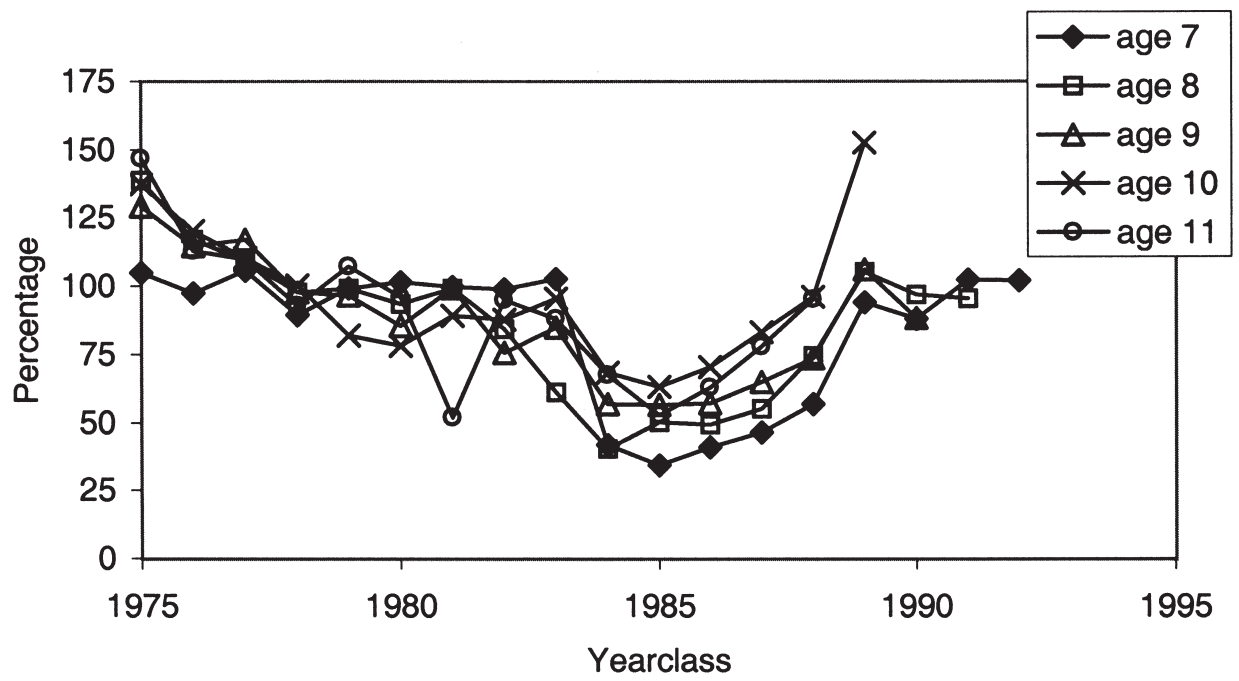

FIG. 6. - Spawning stock numbers at age of individual year-classes expressed as percentage of the mean of the 1975-83 year-classes. 
sistent at all ages. However, the 1984-85 year-classes decreased with age relative to other year-classes, especially from age 5 to age 7 (Fig. 3). As comparison, the 1989 (and partly 1988) and subsequent year-classes increased with age relative to the other year-classes (Fig. 3). The low abundance of the 1984/85-88 year-classes at older age was also recognised in the spawning stock. Figure 6 shows how this obvious year-class effect influenced spawning stock at age. It is worth noting that year-classes from 1989 onwards contributed to the spawning stock at the same level as the year-classes in the early 1980's.

In order to compare the occurrence of these relatively poor year-classes to possibly unreported catches, Table 1 shows the variation in effort and landings from the Norwegian shrimp trawl fishery in Svalbard waters during the last 20 years. While effort peaked in 1985-87, landings of Greenland halibut did not increase until 1990-92, when effort was moderate. Until 1993 this fishery was conducted with small-meshed bottom trawl without sorting grid. From 1993 onwards landings of Greenland halibut in this fishery has been on a low level due to the use of sorting grid.

The XSA estimates were based on catch statistics from age 3 and older. The shrimp trawl fishery at Svalbard may have caught fish at age 0-1 and such catches may have been seriously under-reported, due to the small size of the fish. Since this fishery peaked in effort during 1985-87 (Table 1), this may have contributed to the low size of some of the poor year-classes. The further reduction of the 1984-85 year-classes from age 5 to 7 is consistent with reported landings from this fishery, which were high in 1990-92 (Table 1).
TABLE 1. - Effort (in thousands of trawling hours), and landings of shrimp (in 1000 tons) and Greenland halibut (in tons) from the Norwegian Shrimp-trawl fishery at Svalbard. *: Since 1993 a sorting grid was used to reduce catches of larger fish. Data from the Norwegian Directorate of Fisheries.

\begin{tabular}{lrrr}
\hline Year & Effort & Shrimp & Gr. halibut \\
\hline 1980 & 18 & 3.3 & 0.0 \\
1981 & 20 & 4.7 & 0.0 \\
1982 & 31 & 6.4 & 3.8 \\
1983 & 64 & 17.4 & 13.7 \\
1984 & 87 & 24.1 & 2.5 \\
1985 & 137 & 36.6 & 19.6 \\
1986 & 183 & 27.4 & 3.0 \\
1987 & 108 & 14.9 & 8.8 \\
1988 & 77 & 10.7 & 6.9 \\
1989 & 93 & 15.5 & 18.4 \\
1990 & 81 & 14.2 & 97.2 \\
1991 & 58 & 8.7 & 446.2 \\
1992 & 49 & 10.9 & 574.7 \\
$1993^{*}$ & 40 & 9.5 & 0.9 \\
$1994^{*}$ & 64 & 13.4 & 0.9 \\
$1995^{*}$ & 60 & 9.2 & 2.2 \\
$1996^{*}$ & 66 & 13.5 & 0.9 \\
$1997^{*}$ & 51 & 12.0 & 0.5 \\
$1998^{*}$ & 49 & 16.3 & 0.5 \\
\hline
\end{tabular}

\section{Variations in the physical environment}

Figure 7 shows that the years 1989-94 had the highest level ever recorded of the three-year running mean NAO-index. Thus, the extraordinary low abundance of Greenland halibut in the survey area co-occurred with extraordinary hydrographical conditions. The reappearance of young fish in the most recent surveys (Fig. 3 upper) is consistent with the reduced NAO-index in later years. Although the years 1989-94 were extreme with respect to the NAO-index, Figure 7 shows that high and low values of the 3-years running mean index has occurred

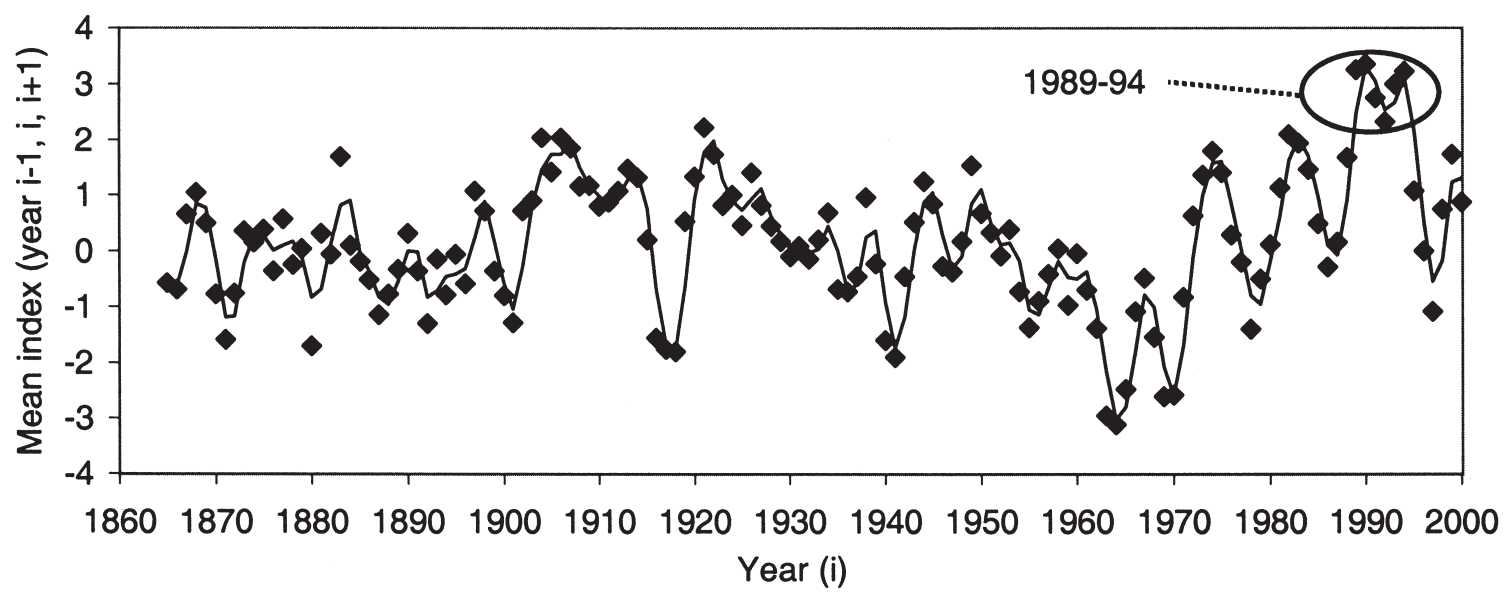

FIG. 7. - Three-year running average of the winter-index of the North Atlantic Oscillation (NAO). The line is a smoothed curve through the data points. 
in alternating periods throughout the time-series. A fast Fourier Transformation of the three years running mean NAO-index yielded a power spectrum with two distinct and significant $(\mathrm{p}<0.01)$ peaks corresponding to periods of 7,6 $(7,4-7,8)$ and 68,5 $(54,8-91,3)$ years respectively. The largest of these periods was estimated with low precision since there were only two periods in the time series.

\section{DISCUSSION}

\section{Changes in juvenile distribution}

The XSA results were similar to the last assessment (ICES, 2001) except for the last year-class (1992) which increased by $10 \%$. However, since the lower age of the tuning data was increased from five to seven, the present XSA did not give results for the last two year-classes in the assessment (1993-94). The last several assessments have shown marked decreasing trend in abundance of the 3-4 final yearclasses included in any year (ICES, 1998, 1999, 2000, 2001). In contrast to these assessments the present XSA shows a stable recruitment pattern over the last four year-classes in the analysis. A consequence is that the discrepancy between the XSA and survey estimates of the 1989 and subsequent yearclasses becomes very apparent.

These results from surveys and the analytical assessment were consistent with previous findings that the 1989-94 year-classes of Greenland halibut were as juveniles displaced to areas further away from the spawning ground compared to both previous and subsequent year-classes (Albert et al., 2001a). The fishery data also supported the conclusion that these year-classes abandoned the western and southeastern Svalbard waters as nursery areas. As they grew older they migrated back to these areas and appeared at age 7 with similar abundance as other year-classes.

The disappearance of catches of juvenile Greenland halibut from Svalbard waters coincided with changes in the way both surveys and commercial fisheries were conducted. From 1989 changes were made in the standard survey trawl, including a new type of ground gear (Engås and Godø, 1989). From 1992 onwards the directed trawl-fishery for Greenland halibut has been closed and by-catch strongly regulated (ICES, 2001). In the shrimp-trawl fishery a sorting grid has been applied since 1993 to reduce by-catches. The grid effectively sorts out Greenland halibut larger than $15-20 \mathrm{~cm}$, i.e. it is not affecting 0 and, partly, 1 year old fish. However, all these technical measures were introduced in a given year and have remained in action since. They can, therefore, only explain year-effects in the catch statistics and not year-class effects as were found here.

\section{A rear occurrence?}

The data suggest that the displacement of these year-classes was an extraordinary situation with no other occurrences during the last 30 years. Although the time series of standardised surveys is limited, several occasional research surveys were made in West-Spitsbergen from 1958 to 1980 (Hognestad, 1961, 1969; Unpublished survey results from the 1970s from Institute of Marine Research; Haug and Gulliksen, 1982). All these surveys reported a high abundance of juvenile Greenland halibut, thus supporting the hypothesis that the displacement represents a rare occurrence.

The distribution shift away from west-Spitsbergen in the early 1990s corresponded with exceptionally high values of the three years running mean NAO index. In fact, the six year-classes 1989-94, with exceptionally low juvenile abundance in Spitsbergen waters, experienced the six highest values of this indicator that has ever been recorded during the 137 years of data. This supports the conclusions of Albert et al. (2001a) that the displacement was related to variations in the physical environment.

Since the species was not recorded in an expedition carried out in west-Spitsbergen waters in 1908 (Hofsten, 1919), Haug and Gulliksen (1982) suggested that the abundance of the juvenile stage may have increased during the $20^{\text {th }}$ Century. However, also the lack of Greenland halibut in the 1908 expedition corresponded with a period of relatively high values of the three years running mean NAO index. In the period before 1980 three of the four years with such high values of this index were during 1905-08 (Fig. 7). It may be that, instead of a general increase during the $20^{\text {th }}$ Century, occurrence of juvenile Greenland halibut in West-Spitsbergen is the usual situation, only interrupted by periodic northwards displacements related to high Atlantic inflow. Our data suggest that such periods may be related to simultaneous peaks in both the short and longer term variability of the North Atlantic Oscillation.

The NAO index is correlated with the strength and temperature of the Atlantic current (Ottersen et 
al., 2000) which carries the spawning products of Greenland halibut from spawning to nursery areas. Kovtsova et al. (1987) showed that the distribution of spawning concentrations of Greenland halibut could vary between years, and suggested that annual variation in temperature may determine the location of the main spawning activity. Adlandsvik et al. (1999) showed that such variation in latitudinal distribution of spawning activity would greatly influence the subsequent distribution of juveniles. The strength of the Atlantic current may thus directly influence where juveniles settle by both regulating the starting point and the speed and duration of the drifting phase.

Possible causal relationship behind the correlation between the NAO-index and juvenile distribution could be related to the latitudinal distribution of spawners or the subsequent larval drift. It seems probable that the distribution shift was linked to changes in the physical environment. Since juvenile Greenland halibut are found on the fringe of areas suitable for surveys, and the dynamics may be linked to the physical environment, the contemporary discussion on climate change should be particularly relevant for the assessment of this species in the future.

\section{Implications for spawning stock estimation}

The relatively low abundance of the 1985-88 year-classes was much more apparent in the present XSA run than in previous assessments (ICES, 1998, 1999, 2000, 2001). The reason for this is the higher and more stable level of subsequent year-classes mentioned above. In previous assessments, when the displacement effect was not accounted for, the XSA gave a continuously decreasing trend from the 1983 year-class to the year-classes in the first half of the 1990s (ICES 1998).

There seems to be two succeeding periods of Greenland halibut year-classes with very different characteristics. While the 1989-94 year-classes were large in VPA and small in catches, the 1984/85-88 year-classes were large in catches (both commercial and in surveys) and small in VPA. Albert et al. (2001a) showed that these periods were characterised with a narrow northwest (1989-94 yearclasses) and a wide southeast (1984-87 year-classes) distribution of age 1 Greenland halibut.

These differences between the two periods may be related to fishing mortality. The 1989-94 yearclasses experienced a very low fishing mortality since as young juveniles they were largely distributed outside the main fishing grounds and as older juveniles were protected by the use of sorting grid in the shrimp fishery. In contrast, the 1984-87 yearclasses were widely found at the main fishing grounds, they experienced as age 0-1 a peak in the shrimp trawl fishery, and they were caught in this fishery also at older ages until sorting grid was introduced in 1993. Although data are lacking, it is assumed that Greenland halibut less than $20 \mathrm{~cm}$ (i.e. age 0 -1) were generally discarded, and are not represented in the landing figures. It is thus probable that the back-calculating algorithm of XSA underestimated abundance at age 0-2 for all year-classes, but especially for the 1985-88 year-classes.

The low abundance of the 1984/85-88 year-classes was responsible for the reduced spawning stock noted in recent assessments. The year-classes from 1989 onwards contributed to the spawning stock at the same level as the year-classes in the early 1980s. Thus, the problem of low spawning stock seen in recent assessments is mainly the result of a closed window of 4-5 year-classes (1984-88) of comparably low abundance, probably at least partly due to fishing. This further demonstrates the importance of not accepting an assessment with trends that are not accounted for in the model. By accounting for the known problem with displaced year-classes at younger age, new insight is generated concerning the development of the spawning stock.

\section{Accuracy of assessments}

The perceived status of the Northeast Arctic Greenland halibut stock has clearly improved during the most recent years (ICES, 1998, 1999, 2000, 2001). This is not primarily due to more promising results from the standard assessment tool that was used. The reason is rather that the assessment procedures have been adjusted (increased age at recruitment) and that more confidence has been given to survey based research and less to the output from the analytical assessments (the XSA runs were only considered as illustrative and did not form the basis for recommendations or predictions). While ICES (1998) assumed that the stock had suffered from recruitment overfishing, Albert et al. (1997, 2001a) showed that recruitment was not that bad after all, and this paper shows that the spawning stock also seems to be better than previously believed. The major failure in previous assessments was related to the belief that the Svalbard surveys 
(Figure 1) covered most of the nursery area and that the survey estimates were equally representative in all years.

Stock assessments based on output from standard analytical software may only be reliable if the nature of the input and tuning data is understood. This paper demonstrates the importance of allocating time to critically analysing all available data, to evaluate if there are trends that may violate the assumptions underlying the assessment method used. Such trends would add uncertainty to the output of the assessment model that may not be included in confidence intervals computed by standard procedures. If such trends are found, it may be worth considering several alternative stock evaluations, conditional on the different relevant hypotheses.

\section{ACKNOWLEDGEMENTS}

Two anonymous reviewers are thanked for valuable comments and corrections to an earlier version of the manuscript. Dr. Alf Harbitz is thanked for help with the Fourier analyses.

\section{REFERENCES}

Albert, O.T. - (in press). Migration from nursery to spawning area in relation to growth and maturation of Greenland halibut (Reinhardtius hippoglossoides) in the Northeast Artic. J. Northwest Atl. Fish. Sci., 31.

Albert, O.T., E.M. Nilssen, K.H. Nedreaas and A.C Gundersen. 1997. Recent variations in recruitment of Northeast Atlantic Greenland halibut (Reinhardtius hippoglossoides) in relation to physical factors. ICES CM 1997/EE:06, 22pp

Albert, O.T., E.M. Nilssen, K.H. Nedreaas and A.C Gundersen. 2001a. Distribution and abundance of juvenile Northeast Arctic Greenland halibut (Reinhardtius hippoglossoides) in relation to survey coverage and the physical environment. ICES J.Mar.Sci., 58: 1053-1062.

Albert, O.T., E.M. Nilssen, A. Stene, A.C. Gundersen and K.H. Nedreaas. - 2001b. Maturity classes and spawning behaviour of Greenland halibut (Reinhardtius hippoglossoides). Fish. Res., 51: 217-228..
Bowering, W.R. and K.H. Nedreaas. - 2000. A comparison of Greenland halibut (Reinhardtius hippoglossoides Walbaum) fisheries and distribution in the Northwest and Northeast Atlantic. Sarsia, 85: 61-76.

Engås, A. and O.R. Godø. - 1989. Escape of fish under the fishing line of a Norwegian sampling trawl and its influence on survey results. J. Cons. Inter. Explor. Mer, 45: 269-276.

Fedorov, K.Y. 1971. Zoogeographic characteristics of the Greenland halibut (Reinhardtius hippoglossoides (Walbaum)). J. Ichthy., 11:971-976.

Haug, T. and B. Gulliksen. - 1982. Size, age, occurrence, growth, and food of Greenland halibut (Reinhardtius hippoglossoides Walbaum) in coastal waters of western Spitsbergen. Sarsia, 68: 293-297.

Hofsten, N. von. - 1919. Zoologische Ergebnisse der schwedischen Expedition nach Spitsbergen 1908 unter Leitung von Prof. G.O.Geer. Teil II. Die Fische des Eisfjords. Kungl. Sv. Vetensk. Akad. Handl., 54(10), 129 pp.

Hognestad, P.T. - 1961. Contributions to the fish fauna of Spitsbergen. I. The fish fauna of Isfjorden. Acta Borealia, A. Scientia 18: 1-36.

Hognestad, P.T. - 1969. Notes on Greenland halibut, Reinhardtius hippoglossoides (Walbaum), in the eastern Norwegian Sea. FiskDir. Skr. Ser. Havunders $\phi$ kelser 15(3): 139-144.

Hurrell, J. W. - 1995: Decadal trends in the North Atlantic Oscillation: Regional temperatures and precipitation. Science, 269, 676-679.

ICES. - 1998. Report of the Arctic Fisheries Working Group, ICES CM 1998/Assess:2, 366 pp.

ICES. - 1999. Report of the Arctic Fisheries Working Group, ICES CM 1999/ACFM:3, $276 \mathrm{pp}$

ICES. - 2000. Report of the Arctic Fisheries Working Group, ICES CM 2000/ACFM:3, 312 pp.

ICES. - 2001. Report of the Arctic Fisheries Working Group, ICES CM 2001/ACFM:2, 340 pp.

Jakobsen, T., K. Korsbrekke, S. Mehl and O. Nakken. - 1997. Norwegian combined acoustic and bottom trawl surveys for demersal fish in the Barents Sea during winter. ICES CM 1997/Y:17, 26pp

Kovtsova, M.V., G.P. Nizovtsev and V.V. Tereshchenko. - 1987. Conditions for the formation of prespawning and spawning Greenland halibut consentrations of the Norwegian-Barents Sea stock. In: H Loeng (ed.), The effect of oceanographic conditions on distribution and population dynamics of commercial fish stocks in the Barents Sea, pp 199-211. Proceedings of the third Soviet-Norwegian symposium, Murmansk, 26-28 May 1986, Institute of Marine Research, Bergen, Norway.

Ottersen, G., B. Ådlandsvik and H. Loeng. - 2000. Predicting the temperature of the Barents Sea. Fish. Ocean. 9(2): 121-135.

Shepherd, J.G. - 1999. Extended survivors analysis: An improved method for the analysis of catch-at-age data and abundance indices. ICES J. Mar. Sci., 56: 584-591.

Stearns, S.D. - 1975. Digital Signal Analysis. Rochelle Park, N.J., Hayden Book Company Inc., 1975, 280pp.

Ådlandsvik, B., A.C. Gundersen, K.H. Nedreaas, A. Stene and O.T. Albert. - 1999. Modelling the advection and diffusion of eggs and larvae of northeast Arctic Greenland halibut. ICES CM 1999/K:03, 20pp. 